\title{
Comparative Study Between Mixed Dyeing of Wool Fiber in One and Two Dye Baths with Natural Indigo and Madder Colorants
}

\author{
Younes Chemchame*, Meryem Belhag, Faouzi Fartmis, Aboubakr Kharchafi \\ Department of Traditional Weaving, Academy of Traditional Arts, Foundation of Hassan II Mosque, Casablanca, Morocco \\ Email address: \\ ychem2@gmail.com (Y.Chemchame), meryem.belhag@gmail.com (M. Belhag), faouzi.fartmis@gmail.com (F. Fartmis), \\ aboubakr.kharchafi@gmail.com (A. Kharchafi) \\ ${ }^{*}$ Corresponding author
}

\section{To cite this article:}

Younes Chemchame, Meryem Belhag, Faouzi Fartmis, Aboubakr Kharchafi. Comparative Study Between Mixed Dyeing of Wool Fiber in One and Two Dye Baths with Natural Indigo and Madder Colorants. American Journal of Physical Chemistry. Vol. 7, No. 1, 2018 , pp. 1-5. doi: 10.11648/j.ajpc.20180701.11

Received: December 23, 2017; Accepted: January 8, 2018; Published: February 9, 2018

\begin{abstract}
The objective of the present study was to compare between the mixed dyeing of wool fiber in one and two dye baths using natural indigo (Indigofera tinctoria) and madder colorants (Rubia tinctorum). Based on the reduction and oxidation reaction conditions under the same dyeing mechanism for the indigo and madder colorants, the exhaustion rate of the mixed dyeing in two dye baths was higher than that for mixed dyeing in one dye bath. The poor exhaustion rate that was achieved when dyeing in a single dye bath indicated the incompatibility of both dyes when mixed in one dye bath. However, both methods achieved a rigid fixation as confirmed by washing-fastness test 105C6A01.
\end{abstract}

Keywords: Wool, Indigo, Madder Colorants, Mixed Dye Bath, Rubia tinctorum, Indigoferra tinctoria, Washing Fastness

\section{Introduction}

Natural dyes produce an extraordinary diversity of rich and complex complementary colors. Natural dyes from plants may contain dozens of compounds and their proportions vary with soil type and weather. The use of natural dyes in textile coloration has been gaining an increased popularity globally, most likely because of environmental concerns, eco-safety, and pollution control. Yarn that is dyed with natural dye such as madder shows a subtle variation of color under the microscope. Yarn that is dyed with the synthetic equivalent of madder (alizarin and purpurin) does not have a wealth of color variation and appears more uniform [1]. However, larger dye quantities and longer dyeing times are required by natural dyes, and the poor fastness properties of almost all color ranges hinder and limit their development and use, particularly in industry.

In this context, various research studies have focused on natural dyes and their application in dyeing natural textiles $[2,8]$. Mohd Yusuf et al. examined the effect of color and fastness properties of wool fibers that were dyed with Rubia cordifolia as a natural dye and Acacia catechu as an anchoring agent. The colorimetric (CIE L*a*b*) and fastness properties were improved considerably by using $A$. catechu as a biomordant and $R$. cordifolia as a natural dye, which may be a profitable option in industrial and commercial spheres [9]. Cristae et al. investigated the effect of some commonly used antioxidants and ultraviolet absorbers on the light fastness of madder, weld, and woad on cotton yarn. They found that vitamin $\mathrm{C}$ and gallic acid were most effective in improving the natural dyes [10].

However, few scientific works exist regarding the mixing of natural dyes. The aim of this study was to study the mixing of two natural dyes, indigo (Indigofera tinctoria) and madder colorants (Rubia tinctorum), in one dye bath, and to compare the efficiency of this method to that of dyeing in two dye baths. The exhaustion and fixation dye rates of the two wool fiber samples were calculated for the two methods. The dyeing process was achieved by the reduction and oxidation mechanism of fixation. The washing fastness of both dyeing procedures (mixed dyeing in one and two dye baths) was tested and compared. 


\section{Experimental}

\subsection{Materials}

\subsubsection{Wool Fiber Features}

Wool fiber was from Boujaâd in Morocco. White fleece was compacted and homogenized into a medium-weight fleece of $1.5-3 \mathrm{~kg}$ and the fiber fineness was 50-60 using the Bradford scale [7,8].

\subsubsection{Natural Dye}

Alizarine and other anthraquinone dyes were extracted from the $R$. tinctorum plant, which grows in southeast Morocco [11]. The extraction method was based on the enzymatic hydrolysis (endogenous conversion) of the dried and powdered root of the plant. The indigo dye was extracted from Indigoferra tinctoria, and purchased from the Association Couleur Garance, Lauris-France.

\subsubsection{Chemicals}

Alkali reagents, sodium hydroxide $(\mathrm{NaOH})$, sodium carbonate $\left(\mathrm{Na}_{2} \mathrm{CO}_{3}\right)$, sodium bicarbonate $\left(\mathrm{NaHCO}_{3}\right)$, and the acidic reagent, acetic acid $\left(\mathrm{CH}_{3} \mathrm{COOH}\right)$, were of analytical grade and were from Lobachemie Company (Mumbai, India), and VWR Prolabo Chemicals Company (FontenaySous Bois, France), respectively. A Marseille soap type was prepared from vegetable oil, and was from a mini supermarket. Sodium chloride $(\mathrm{NaCl})$ was of analytical grade and was from Solvachim (Casablanca-Morocco).

\subsubsection{Argan's Pulp}

The reducing agent, Argan's pulp, was collected from around an Argan tree from Essaouira in South Morocco. This natural product was composed of $20 \%$ reducer sugar, $13 \%$ cellulose, $6 \%$ protein, $2 \%$ fat, and $4 \%$ latex (comprised of $86 \%$ cis-polyisoprene: rubber) $[12,13]$.

\subsubsection{Spectrophotometry}

An ultraviolet-visible spectrophotometer (Thermo, Helios Epsilon) was used at 325-1100 nm with a spectral bandwidth of $1 \mathrm{~nm}$.

\subsection{6. $\mathrm{pH}$ Meter}

A Henne AD1000 pH meter was used. This multimeter can measure $\mathrm{pH}$, oxidation-reduction potential, and temperature.

\subsubsection{Bath}

A $250-\mathrm{mL}$ flask was used. Heating was by a thermostat hotplate (Scilogex MS-H280-Pro).

\subsubsection{Filter}

The filter that was used in this study is a metallic sieve (15-mm diameter).

\subsection{Dyeing Process with Indigo and Madder in Two Baths}

\subsubsection{Preparation of the Reducer}

Argan's pulp (30 g) was added into $100 \mathrm{~mL}$ of distilled water and heated at $95^{\circ} \mathrm{C}$ for $30 \mathrm{~min}$. The extract was filtered by using a metallic sieve.

\subsubsection{Preparation of Indigo Vat}

Indigo $(0.1 \mathrm{~g})$ was placed in $100 \mathrm{~mL}$ of distilled water that contained $1.2 \mathrm{~g}$ of sodium carbonate and $1.2 \mathrm{~g}$ of sodium bicarbonate, at $\mathrm{pH} 10.86$ and $45^{\circ} \mathrm{C}$ for $30 \mathrm{~min}$ and at a ratio of $1 / 100$. Then $4 \mathrm{~g}$ of fructose $(100 \mathrm{~mL}$ of prepared extract from $30 \mathrm{~g}$ of Argan's pulp) and $1 \mathrm{~g}$ of $\mathrm{NaCl}$ were added.

\subsubsection{Dyeing in the Indigo Vat}

Wool yarn (1 g) was soaked and wrung before being placed in the indigo vat. The dyeing conditions were $100 \mathrm{~mL}$ at $45^{\circ} \mathrm{C}$ for $30 \mathrm{~min}$ and a ratio of $1 / 100$.

\subsubsection{Preparation of Madder Extract Dyes}

Plant sample $(5 \mathrm{~g})$ was stirred in $100 \mathrm{~mL}$ of water at $45^{\circ} \mathrm{C}$ for $90 \mathrm{~min}$. The solution was filtered using a metallic sieve and well-preserved to the dyeing phase. The residue was dried and weighed to calculate the approximate amount of dye that exists in the initial madder plant.

\subsubsection{Preparation of Madder Dye Bath}

The dyeing conditions for the madder dye bath were 100 $\mathrm{mL}$ of dye (extract prepared from $5 \mathrm{~g}$ R. tinctorum in $100 \mathrm{~mL}$ water), $1.2 \mathrm{~g}$ sodium carbonate, and $1.2 \mathrm{~g}$ sodium bicarbonate, $\mathrm{pH} 9.65$, at $60^{\circ} \mathrm{C}$ for $30 \mathrm{~min}$ and with a ratio of $1 / 100$.

\subsubsection{Reduction of Madder Dye Bath}

The reducing conditions of the madder dye bath were 100 $\mathrm{mL}$ of prepared madder dye bath, $3 \mathrm{~g}$ of fructose (or $30 \mathrm{~g}$ of Argan's pulp extract), $10 \mathrm{~g} / \mathrm{L} \mathrm{NaCl}$ at $45^{\circ} \mathrm{C}$ for $30 \mathrm{~min}$ and with a liquid ratio of $1 / 100$.

\subsubsection{Dyeing in the Reduced Madder Dye Bath}

Wool yarn $(1 \mathrm{~g})$ that had been dyed with indigo was placed in the reduced madder dye bath, at $45^{\circ} \mathrm{C}$ for $30 \mathrm{~min}$ with a liquid ratio $1 / 100$.

\subsubsection{Spectral Analysis}

\section{Spectrophotometer calibration}

Spectrophotometer calibration was achieved by using a standard solution that was prepared according to the mass of wool yarn, the concentration of reducer (fructose or Argan's pulp), $\mathrm{NaCl}$, and alkali $(\mathrm{NaOH}$, sodium carbonate, and sodium bicarbonate) that was added to the dye baths.

Measurement of dye exhaustion and fixation rate

$1 \mathrm{~mL}$ was removed of solution from each dye bath for measurement. Each sample was diluted to $10 \mathrm{~mL}$ using the prepared standard solutions. The absorbance measurements are shown in Tables 1 and 2. The absorbances were measured at $380 \mathrm{~nm}$.

\subsection{Dyeing Process with Indigo and Madder in One Bath}

\subsubsection{Preparation of Indigo Vat}

Indigo $(0.05 \mathrm{~g})$ was stirred in $50 \mathrm{~mL}$ distilled water at $45^{\circ} \mathrm{C}$ for $10 \mathrm{~min}$ to reduce the indigo grain size.

\subsubsection{Preparation of Madder Colorants Bath}

Madder plant $(5 \mathrm{~g})$ was macerated in $100 \mathrm{~mL}$ distilled water at $40^{\circ} \mathrm{C}$ for $2 \mathrm{~h}$, then filtered by using a metallic sieve. 
Only $50 \mathrm{~mL}$ was taken from the prepared extract for use in the mixture dyeing with indigo.

\subsubsection{Preparation of Reduced Mixed Dye Bath}

The reducing conditions of the mixed dye bath were 100 $\mathrm{mL}$ prepared indigo $(50 \mathrm{~mL})$ and madder colorants $(50 \mathrm{~mL})$ in the dye bath, $3 \mathrm{~g}$ fructose (or $30 \mathrm{~g}$ of Argan's pulp extract), $1 \mathrm{~g} \mathrm{NaCl}, 1.2 \mathrm{~g}$ sodium carbonate, and $1.2 \mathrm{~g}$ sodium bicarbonate, $\mathrm{pH} 10.73$, at $45^{\circ} \mathrm{C}$ for $30 \mathrm{~min}$ and a liquid ratio of $1 / 100$.

\subsubsection{Dyeing in the Mixed Dye Bath}

Wool yarn (1 g) was soaked and wrung before being placed in the mixed dye bath. The dyeing conditions were $100 \mathrm{~mL}$ at $45^{\circ} \mathrm{C}$ for $30 \mathrm{~min}$ and a liquid ratio of $1 / 100$.

\subsubsection{Cold Rinse}

Rinsing of the samples (for mixed dyeing in one and two baths) was conducted at the end of the dyeing process to remove dyes from the fiber and inter-surfaces and to neutralize the alkaline medium.

\subsubsection{Oxidation and Rinse}

Oxidation was achieved for samples in open air for $15 \mathrm{~min}$ for the rinsing phases. At the end of the dyeing process, two successive rinses were conducted in cold water.

\subsubsection{Acidification (Neutralization)}

Samples were treated in acidic solution at $\mathrm{pH} 6.5$ with $\mathrm{CH}_{3} \mathrm{COOH}(30 \%)$.

\subsubsection{Drying}

Samples were dried in a sterile environment at $60^{\circ} \mathrm{C}$ and $80^{\circ} \mathrm{C}$.

\subsubsection{Soaping}

Samples were treated with $0.6 \mathrm{~g} / \mathrm{L}$ Marseille soap at $60^{\circ} \mathrm{C}$ for $15 \mathrm{~min}$, with a liquid ratio of $1 / 100$. The soaping step was used to test the washing fastness of the samples that were dyed in the mixed dye bath.

\subsubsection{Washing Fastness}

The washing fastness was determined at $40^{\circ} \mathrm{C}$ over $30 \mathrm{~min}$ according to ISO 105-C6:A1S [14].

\section{Results and Discussion}

\subsection{Exhaustion Rate of Indigo in Dye Bath}

The absorbances and concentrations of the initial and final dye bath are presented in Table 1 .

Table 1. Exhaustion rate of indigo in dye bath.

\begin{tabular}{llll}
\hline & Initial dye bath & Final dye bath & Exhaustion rate $((\mathbf{C i}-\mathbf{C f}) / \mathbf{C i}) * 100(\%)$ \\
\hline Indigo absorbance & 0,213 & 0.125 & \multirow{2}{*}{66.24} \\
Indigo concentration $(\mathrm{g} / \mathrm{L})$ & 0.631 & 0.213 & \\
\hline
\end{tabular}

The calculated concentration of indigo $(0.631 \mathrm{~g} / \mathrm{L})$ was lower than the experimental concentration that was introduced into the dye bath $(1 \mathrm{~g} / \mathrm{L})$. This can be explained by the incomplete solubility of indigo at $\mathrm{pH} 10.86$.

\subsection{Exhaustion Rate of Madder Colorants in Dye Bath}

The absorbances and concentrations of the initial and final dye baths are presented in Table 2 .

Table 2. Exhaustion rate of madder colorants in dye bath.

\begin{tabular}{|c|c|c|c|}
\hline & Initial dye bath & Final dye bath & Exhaustion rate $((\mathrm{Ci}-\mathrm{Cf}) / \mathrm{Ci}) * 100(\%)$ \\
\hline Madder colorants absorbance & $\begin{array}{l}0.526 \\
4534\end{array}$ & $\begin{array}{l}0.409 \\
3530\end{array}$ & 22.14 \\
\hline
\end{tabular}

The exhaustion rate of the madder colorants was lower because of the high alkaline medium. The alizarine and other anthraquinones in the madder plant are soluble in the high alkaline medium.

\subsection{Exhaustion Rate of Indigo and Madder Colorants in Mixed Dye Bath}

The concentrations of the initial and final dye bath are presented in Table 3.

Table 3. Exhaustion rate of indigo and madder colorants in mixed dye bath.

\begin{tabular}{|c|c|c|c|}
\hline & Initial dye bath & Final dye bath & Exhaustion rate $((\mathrm{Ci}-\mathrm{Cf}) / \mathrm{Ci}) * 100$ \\
\hline Concentration of indigo and madder colorants in one dye bath $(\mathrm{g} / \mathrm{L})$ & 18.84 & 16.98 & $10.0 \%$ \\
\hline
\end{tabular}

The exhaustion rate was considerably lower. This may result from the low absorbance of the madder colorants towards the fiber in the high alkaline medium.

\subsection{Exhaustion Rate Comparison of Indigo and Madder Colorants in One and Two Dye Baths}

The summary of measurements of the exhaustion rate of indigo and madder colorants in one and two dye baths are given in Table 4 
Table 4. Comparative exhaustion rates of indigo and madder colorants for dyeing in one and two dye baths.

\begin{tabular}{llll}
\hline Samples & $\begin{array}{l}\text { Exhaustion rate of indigo in the } \\
\text { first dye bath }((\mathbf{C i}-\mathbf{C f}) / \mathbf{C i}) * \mathbf{1 0 0}\end{array}$ & $\begin{array}{l}\text { Exhaustion rate of madder colorants in } \\
\text { the second dye bath }((\mathbf{C i}-\mathbf{C f}) / \mathbf{C i}) * \mathbf{1 0 0}\end{array}$ & $\begin{array}{l}\text { Exhaustion rate of indigo and madder colorants } \\
\text { in one mixed dye bath }(\mathbf{C i}-\mathbf{C f}) / \mathbf{C i}) * 100\end{array}$ \\
\hline $\begin{array}{l}\text { Dyeing in two } \\
\text { dye baths }\end{array}$ & $66.2 \%$ & $22.1 \%$ & - \\
$\begin{array}{l}\text { Dyeing in one } \\
\text { dye bath }\end{array}$ & - & - & $10.0 \%$ \\
\hline
\end{tabular}

It was concluded that the mixed dyeing in two dye baths with indigo and madder colorants achieved a more intense and uniform coloration. The results were attributed to the difference in optimal dyeing conditions between the indigo and madder colorants. The $\mathrm{pH}$ of the medium was the most important factor that caused this difference. Therefore, indigo required a high alkaline medium to achieve complete solubility in a dye bath. In contrast, the madder colorants had a lower substantivity towards wool fiber in this high alkaline medium.

\subsection{Fixation of Indigo and Madder Colorants in Two Dye Baths}

Dyes that were removed from the sample that were dyed in two baths (indigo and madder colorants) during the soaping phase were very little in the dyeing process, and therefore, they were not taken into account in the calculation of the fixation dye rate. Complete fixation was achieved.

\subsection{Fixation of Indigo and Madder Colorants in One Dye Bath}

Dyes that were removed from the sample that was dyed in one dye bath during the soaping phase were very little during the dyeing process, therefore, it was believed that complete fixation was achieved. For both methods, the high dye fixation was attributed to the insoluble form of dyes inside the fiber, which was formed after oxidation and achieved important physicochemical interactions (hydrogen bonds) and physical interactions (Van der Waals interactions) with the fiber.

\subsection{Washing Fastness}

Measurements that were obtained for the two soaping samples are presented in Table 5.

Table 5. Washing fastness of indigo and madder colorants for dyeing in one and two baths.

\begin{tabular}{|c|c|c|c|c|c|c|c|}
\hline \multirow[t]{2}{*}{ Samples } & \multicolumn{6}{|c|}{ Washing fastness (assessing staining) } & \multirow{2}{*}{ Washing fastness (assessing change in color) } \\
\hline & WO & PAC & PES & $\mathbf{P A}$ & $\mathrm{CO}$ & $\mathbf{C A}$ & \\
\hline Dyeing in two baths & 5 & 5 & 5 & 5 & 5 & 5 & $4-5$ \\
\hline Dyeing in one bath & 5 & 5 & 5 & 5 & 5 & 5 & $4-5$ \\
\hline
\end{tabular}

The values from these experiments confirm the solid fixation of dyes as described previously.

An excellent washing fastness was achieved for the combined method. In fact, the reduction method (vat system) of the indigo and madder colorants in the combined method improved the diffusion and fixation on the fiber and converted the dye into a non-soluble molecule inside the fiber. Both methods achieved a similar fastness. This was explained by the seam fixation mechanism (reduction and oxidation reactions).

\section{Conclusions}

This study confirmed the incompatibility of mixing indigo and madder colorants in one dye bath. However, dyeing in two dye baths yielded a higher dye exhaustion rate. This result was attributed to the different optimal dyeing conditions of the indigo and madder colorants. The indigo required a high alkaline medium to achieve complete solubility in the dye bath. In contrast, the madder colorants had a lower substantivity towards wool fiber in such a high alkaline medium. Both dyeing methods (mixed dyeing in one and two dye baths) achieved a rigid fixation of dyes and an excellent degree of washing fastness. This behavior may result from the fixation mechanism of indigo and madder colorants, which is based on the reduction and oxidation reactions. After oxidation, the dyes were converted to an insoluble form inside the fiber by the formation of stable interactions (hydrogen bonds and Van der Waals interactions) with different amino acids of the wool fiber.

\section{References}

[1] www.wildcolours.co.uk/html/natural_dyes_comparison.html.

[2] Lydie Nencki, La science des teintures animales et végétales, 1980.

[3] H. Bôhmer H., Natural Dyes and Textiles (Koekboya) Ed. Weppert, Schweinfurt, 2002, p 244.

[4] Goverdina C. H., Derksen, Teris A. Van Beek, Rubia tinctorum L, Studies in Natural Products Chemistry, 26, Part G, 2002, pp 629-684.

[5] Elisabet Dument, Teindre avec les plantes (les plantes tinctoriales et leur utilisation), Edt. Ulmer, 2010, p 9.

[6] Marie Marquet, Guide des teintures naturelles, Edt. Belin, 2011, p 41-42.

[7] Younes Chemchame, Mohamed El Moudden, Anass Mansar. Dyeing Wool Fiber with Natural Alizarin in a Vat System, American Journal of Applied Chemistry, Vol. 4, No. 5, 2016, pp. 170-173. 
[8] Younes Chemchame, Adil Errabhi, Amal Makhloufi, Optimization of the Dyeing Conditions for Wool Fiber with Natural Indigo Using the Argan's Pulp, American Journal of Chemistry and Application. Vol. 2, No. 5, 2015, pp. 70 - 74.

[9] Mohd Yusuf, Faqeer Mohammad, Mohd Shabbir, Eco-dyeing of wool with Rubia cordifolia root extract: Assessment of the effect of Acacia catechu as biomordant on color and fastness properties, Textiles and Clothing Sustainability, 2016, Vol 2, $\mathrm{N}^{\circ} 1$.

[10] Daniela Cristea and Gerard Vilarem, Improving light fastness of natural dyes on cotton yarn, Dyes and pigments, Vol. 70, Issue 3, 2006, pp. 238-245.

[11] J. Bellakhdar, La Pharmacopée marocaine traditionnelle: Médecine arabe ancienne et savoirs populaires, Paris, Ibis Press, (1997) Z. K. Fellat, S. Smoughen, and R. Maurin, Etude de la pulpe du fruit de l'arganier (argania spinosa) du
Maroc. Matières grasse et latex, Actes Inst. Agron. Vet. (1987), 7.

[12] Z. K. Fellat, S. Smoughen, and R. Maurin, «Etude de la pulpe du fruit de l'arganier (argania spinosa) du Maroc. Matières grasse et latex » Actes Inst. Agron. Vet. (1987), 7.

[13] M. Faez M., Modélisation de la répartition du transfert des métaux lourds et des oligoéléments dans les sols forestiers, l'huile d'argan et dans les différentes parties d'arganier, Thèse d'état, Fac. Sci. Unv. Mohamed V Agdal-Rabat-Maroc, (2012).

[14] Iso 105-C06:2010 Textiles; Tests for colour fastness. Part C06: Colour fastness to domestic and commercial laundering (Basel: ISO, 2010). 